\title{
A FIELD STUDY ON THE EFFECTS OF RESIDUAL SPRAY OF ENCAPSULATED FENITROTHION ON ANOPHELES MINIMUS POPULATION IN PHARE PROVINCE, NORTHERN THAILAND
}

\author{
Wannapa SuWonkerd ${ }^{1}$, SOMSAK PRAJAKWong ${ }^{1}$, Yoshio Tsuda ${ }^{2}$ \\ AND MASAHIRO TAKAGI ${ }^{2}$ \\ Received June 9, 1997/Accepted July 17, 1997
}

\begin{abstract}
A field study was carried out in 2 villages of Phare Province, Thailand to evaluate effect of the residual spraying of a microcapsulated formulation of $20 \%$ fenitrothion (Sumithion $20 \mathrm{MC}{ }^{\circledR}$ ) on Anopheles minimus populations. In the treatment village, houses were sprayed with $1 \mathrm{~g} / \mathrm{m}^{2}$ of fenitrothion, except for 2 houses which were selected to spray with $0.5 \mathrm{~g} / \mathrm{m}^{2}$ of fenitrothion for comparative bio-assay test. The results of bio-assay test showed that mortality of $A n$. minimus was $100 \%$ in $1 \mathrm{~g} / \mathrm{m}^{2}-30$ miniutes until 4 months after the spray. The growth rate of $A n$. minimus population during the first 4 months of the study period in the treatment village was lower than that in the control area. These results suggested that the residual spray of fenitrothion microcapsules at the beginning of the dry season was effective at least for 4 months after the spray and could suppress the density of An. minimus.
\end{abstract}

Key words: Residual spray, Fenitrothion, Microcapsule, Anopheles minimus, Thailand

\section{INTRODUCTION}

DDT has played an important role in the vector control until recent years in developing countries. However, the behavioral and/or physiological resistance of mosquitoes have been developed by the continuous application of DDT (WHO, 1992). It has become a serious problem in vector control in many countries, in addition to the side effects of DDT on the surrounding environment through the biological concentration (Curtis, 1994).

In Thailand DDT has been used on a large scale for the malaria vector control since 1952. The physiological and behavioral resistance to DDT have been observed in some anopheline species in Thailand (WHO, 1970, 1992). The screening of alternative insecticide to DDT has become an important subject in the vector control, though it has been believed that the major malaria vectors, Anopheles minimus and An. dirus, have been still susceptible to DDT (Ismail et al., 1974, 1975; Nutsathapana et al., 1986). Since 1982 fenitrothion has been introduced to some areas as another candidate of insecticide. In 1988 a field study on the response of $A n$. dirus to DDT and fenitrothion was conducted and the results suggested the presence of behavioral resistance (Suwonkerd et al., 1990). In this study effects of the residual spray of a microcapsulated formulation of $20 \%$ fenitrothion (Sumithion $20 \mathrm{MC}^{\circledR}$ ) on An. minimus were examined in northern Thailand.

\section{MATERIALS AND METHODS}

The study was carried out from October 1995 to September 1996 in 2 villages in Saeipt Canton, Song District, Phare Province, $245 \mathrm{~km}$ east of Chiangmai City, Thailand. One village (No. 8 Ban Tawa) where 67 houses were situated and the population $=272$ was selected as the treatment area. The other village (No. 5 Ban Mae Ten) was selected as the control area where 89 houses were situated and the population was 340 .

Among the houses in the treatment area, 2 houses were selected to spray with $0.5 \mathrm{~g} / \mathrm{m}^{2}$ of encapsulated fenitrothion for the comparative bio-assay test and the other houses were sprayed with $1 \mathrm{~g} / \mathrm{m}^{2}$ in October, 1995 .

Before the insecticide spray, mosquito collections were performed in 4 successive nights. Monthly mosquito collection (4 nights) was conducted by 3 different methods for 1 year after the spray. Using human baits,

1) Office of Vector Borne Disease Control, Region 2, Ministry of Public Health, Thai Government, Amphur Muang, Chiangmai 50200, Thailand

2 ) Department of Medical Entomology, Institute of Tropical Medicine, Nagasaki University, 1-12-4 Sakamoto, Nagasaki 852, Japan 
2 different collections, indoor and outdoor human bait collections were made from 18:00 to 24:00 at 2 fixed houses. A pair of collectors sat inside and outside of the houses and landing mosquitoes were collected by an aspirator hourly for $50 \mathrm{~min}$. In the 3 rd collection method (the animal bait collection), a cow was tethered inside a gauze net $(4 \times 4 \times 2 \mathrm{~m})$, which was similar to the one described by Service (1993), and one collector caught mosquitoes landing in and out of the net using an aspirator at every $15 \mathrm{~min}$. During the collection period relative humidity and temperature were recorded.

Following WHO (1970) the bio-assay test was made every month for 2 different dosage $\left(0.5\right.$ and $1 \mathrm{~g} / \mathrm{m}^{2}$ of fenitrothion) and 2 different periods of exposure (3 and $30 \mathrm{~min}$ ) using 100-200 An. minimus adults reared in the laboratory. The test was duplicated in each combination.

For the bio-assay test the mortality was calculated for each replication and the average of the 2 replications was shown in the table. The average number of $A n$. minimus per half night was calculated for each collection method and the growth rate of $A n$. minimus population during the first 4 months of the study period was estimated by applying log regression analysis to the average number of $A n$. minimus +1 .

\section{RESULTS AND DISCUSSION}

The results of bio-assay test showed that mortality of An. minimus was $100 \%$ until 3 months after the spray in all combinations (Table 1). Only the combination of the higher dosage with $30 \mathrm{~min}$ exposure showed $100 \%$ of mortality until 4 months after the spray. The difference in the effective period between 2 dosage, $0.5 \mathrm{~g} / \mathrm{m}^{2}$ and
Table 1 The result of bio-assay test of $A n$. minimus on the residual deposits of $20 \%$ microcapsulated fenitrothion sprayed from October 1995 to September 1996 in Phare, Thailand

\begin{tabular}{cccccc}
\hline \multirow{2}{*}{$\begin{array}{c}\text { Time after } \\
\text { spray (month) }\end{array}$} & \multicolumn{2}{c}{$0.5 \mathrm{~g} / \mathrm{m}^{2 *}$} & & \multicolumn{2}{c}{$1 \mathrm{~g} / \mathrm{m}^{2 *}$} \\
\cline { 2 - 3 } \cline { 5 - 6 } $\min ^{* *}$ & $30 \min ^{* *}$ & & $3 \min ^{* *}$ & $30 \min ^{* *}$ \\
\hline 0 & 100 & 100 & & 100 & 100 \\
2 & 100 & 100 & & 100 & 100 \\
3 & 100 & 100 & & 100 & 100 \\
4 & 100 & 100 & & 100 & 100 \\
5 & 9 & 49 & & 52 & 100 \\
7 & 7 & 44 & & 12 & 95 \\
9 & 9 & 40 & & 14 & 78 \\
10 & 10 & 25 & & 17 & 47 \\
11 & 11 & 35 & & 15 & 48 \\
& 14 & 34 & & 18 & 40
\end{tabular}

The total number of mosquitoes used in each test was 100-200 and mortality rate of the control mosquitoes was 0 in all the bioassay test.

* Dosage of fenitrothion

** Exposure time

$1 \mathrm{~g} / \mathrm{m}^{2}$, was about 1 month, and the higher dosage always showed the higher mortality.

The temporal changes in the number of $A n$. minimus collected by 3 different methods are depicted in Fig. 1. The density of $A n$. minimus declined after the insecticide spray, except for the result of animal bait collection in the control area, and started to increase in May 1996. Although the observed temporal changes in the density may be partly ascribed to the seasonal prevalence of this species in northern Thailand (Takagi et al., 1995; Suwonkerd et al., 1995), the density of indoor and outdoor collection in the treatment area decreased more rapidly from November to December 1995 than the control area.
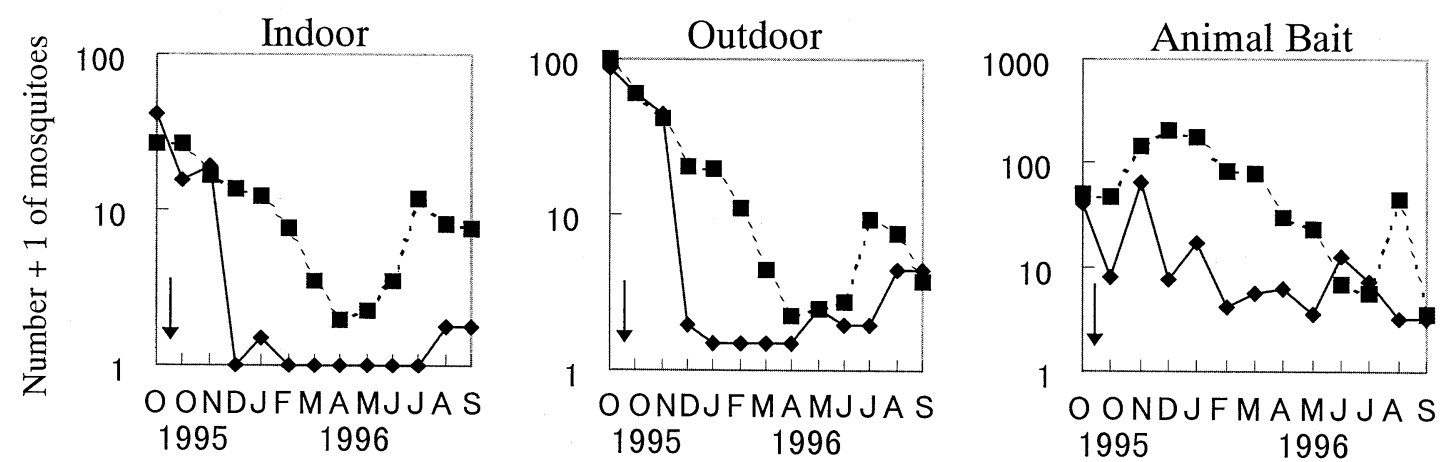

Figure 1 Temporal changes in the number of $A n$. minimus/half night collected by 3 different methods from October 1995 to September 1996 in 2 villages in Phare, Thailand. The solid and dashed line shows the result in the treatment and control village, respectively. The arrow shows the day of residual spraying of $1 \mathrm{~g} / \mathrm{m}^{2}$ of microcapsulated fenitrothion in the treatment village. 
Table 2 Results of log regression analysis of the temporal changes in the number of An. minimus collected by 3 different methods in the control and treatment area* from October 1995 to February 1996, Phare, Thailand

\begin{tabular}{|c|c|c|c|c|c|c|}
\hline & \multicolumn{2}{|c|}{ Indoor } & \multicolumn{2}{|c|}{ Outdoor } & \multicolumn{2}{|c|}{ Animal Bait } \\
\hline & Treatment & Control & Treatment & Control & Treatment & Control \\
\hline Slope $(b)$ & -0.35 & -0.123 & -0.468 & -0.18 & -0.111 & 0.059 \\
\hline S.E. & 0.126 & 0.017 & 0.132 & 0.023 & 0.153 & 0.09 \\
\hline $\begin{array}{l}\text { Growth rate/ } \\
\text { month }\left(10^{b}\right)\end{array}$ & 0.447 & 0.753 & 0.340 & 0.661 & 0.775 & 1.146 \\
\hline $\begin{array}{l}\text { Correlation } \\
\text { coefficient }(r)\end{array}$ & 0.721 & 0.944 & 0.808 & 0.953 & 0.149 & 0.125 \\
\hline
\end{tabular}

*Houses were sprayed with $1 \mathrm{~g} / \mathrm{m}^{2}$ of microcapsulated fenitrothion in October 1995.

Because the bio-assay test showed that the sprayed insecticide was effective at least for the first 4 months of the study period, the growth rate of the average number of $A n$. minimus during the first 4 months (from October 1995 to February 1996) was estimated and compared in Table 2. Both indoor and outdoor collections, the slope of log regression line $(b)$ in the treatment area was significantly smaller than that in the control area. The growth rate in the control area was estimated as 0.753 and $0.661 /$ month for indoor and outdoor collections, respectively, and that in the treatment area was 0.447 and $0.340 /$ month for indoor and outdoor collections, respectively. Though the log regression was not significant in the animal bait collection, the difference between the treatment and control area was clear; the density of $A n$. minimus in the control area showed gradual increase whereas that in the treatment area showed decreasing tendency during the first 4 months of the study period (Fig. 1).

All the results suggested that the residual spray of capsulated fenitrothion at the beginning of the dry season was effective at least for 4 months after the spray and could suppress the density of An. minimus. However the present study started from the declining period of An. minimus population, thus, the effect of the insecticide sprayed might be overestimated in this study. Additional field studies in the increasing period of $A n$. minimus population will be needed to evaluate the effect of the residual spray of microcapsulated fenitrothion in malaria vector control throughout the year.

\section{ACKNOWLEDGEMENT}

We thank Sumitomo Co. Ltd for financial support and all field staffs of Office of Vector Borne Disease Control, Region 2, Chiangmai, Thailand for their continuous help for the field study.

\section{REFERENCES}

1) Curtis C.F. (1994): Should DDT continue to be recommended for malaria vector control? Med. Vet. Entomol., 8, 107-112

2 ) Ismail, I.A.H., Notananda, V. and Schepens, J. (1974): Studies on malaria and response of Anopheles balabacensis and Anopheles minimus to DDT residual spraying in Thailand. Part 1; Pre-spraying observations. Acta. Trop., 31, 129-164

3 ) Ismail, I.A.H., Notananda, V. and Schepens, J. (1975): Studies on malaria and response of Anopheles balabacensis and Anopheles minimus to DDT residual spraying in Thailand. Part 2; Post-spraying observations. Acta. Trop., 32, 206-231

4 ) Nutsathapana, S., Sawasdiwongphorn, P., Chitprarop, U. and Cullen, J.R. (1986): The behavior of Anopheles minimus Theobald (Diptera: Culicidae) subjected to differing levels of DDT selection pressure in northern Thailand. Bull. Entomol. Res., 76, 303-312

5 ) Suwonkerd, W., Amg-Ung, B., Rimwangtrakul, K., Wongkattiyakul, S., Kattiyamongkool, B., Chitprarop, U. and Takagi, M. (1990): A field study on the response of Anopheles dirus to DDT and Fenitrothion sprayed to huts in Phetchabun Province, Thailand. Trop. Med., 32, $1-5$

6 ) Suwonkerd, W., Takagi, M., Amg-Umg, B. and Prajakwong, S. (1995): Seasonal and spatial distribution of 3 malaria vectors at three mountainous villages in north Thailand. Jpn. J. Trop. Med. Hyg., 23, 183-187

7 ) Takagi, M., Suwonkerd, W., Tsuda, Y. Kamboonruang, C., Chitpralop, U., Nakazawa, S., Kanbara, H. and Wada, Y. (1995): Seasonal density and malaria vector competence of Anopheles minimus and other anophelines at a shallow valley in north Thailand. Jpn. J. Trop. Med. Hyg., 23, 177-182

8) WHO (1970): Resistance of vectors and reservoirs of disease to pesticides. WHO technical report series No. 737, Geneva

9) WHO (1992): Vector resistance to pesticides. WHO technical report series No. 818 , Geneva 